\title{
Liquid Fuels From Plants
}

\section{Can we Meet Our Petroleum Needs from Plants?}

\section{G Nagendrappa}

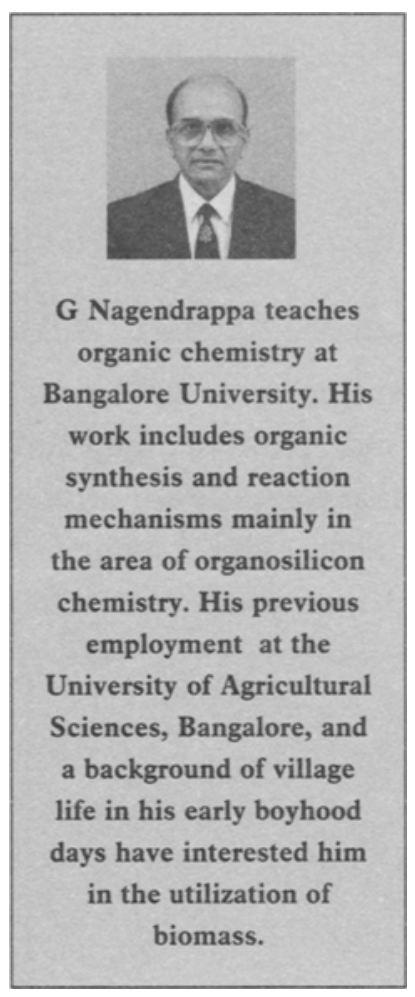

Ever since man discovered the use of fire, the plants remain to this day as an important and reliable source of renewable energy. Through photosynthesis, the plants trap the light energy of the sun, the ultimate source of most of the terrestrial energy. The plant material, as is the common knowledge, is used as solid fuel. All over the world about 2.5 billion tons of wood and crop residues are burned directly to get heat. However, exploitation of plants to obtain the liquid fuels requires physical, chemical and biochemical techniques. The technology involved in this conversion may be simple or difficult depending on the nature of the biomass source and the kind of liquid fuel finally produced. Three types of liquid fuels can be derived from plants, viz., (i) the vegetable or fatty oils, (ii) alcohol (ethanol), and (iii) liquid hydrocarbons.

\section{Vegetable Oils}

Until the mining of petroleum was developed during the nineteenth century, vegetable oils, especially the non-edible varieties (see Table 1), formed an important source of heat and light. Usually the seeds, which store much higher concentration of fatty oil than any other part of the plant, are used for extracting the oil. Most of the common oil seeds contain $20-30 \%$ of oil by weight, and in some cases up to $42 \%$. The techniques for the extraction of oil from the seeds are relatively simple and may involve one or more of the following processes, viz., (i) pressing, (ii) cooking in water, and (iii) solvent extraction. Some of the non-edible oils that are being tried as transport fuel for vehicles are the oils of Pongamia, mahua, neem and fatropha (see Box 1).

Vegetable oils are the esters of glycerol and fatty acids. In this form they are not quite suitable as substitutes for petrol or 


\begin{tabular}{|c|c|c|c|c|}
\hline Fatty acid & $\begin{array}{l}\text { No. of carbons with } \\
\text { degree of unsaturation }\end{array}$ & Neem oil & Pongamia oil & Jatropha oil \\
\hline Myrisitic & $\mathrm{C}_{14: 0}$ & $0.2-2.6$ & - & $0.5-1.4$ \\
\hline Palmitic & $\mathrm{C}_{16: 0}$ & $13.6-16.2$ & $3.7-7.9$ & $12.0-17.0$ \\
\hline Stearic & $\mathrm{C}_{18: 0}$ & $14.4-24.1$ & $2.4-8.0$ & $5.0-9.7$ \\
\hline Oleic & $\mathrm{C}_{18: 1}$ & $49.1-61.9$ & $44.5-71.3$ & $37.0-63.0$ \\
\hline Linoleic & $\mathrm{C}_{18: 2}$ & $2.3-15.8$ & $10.8-18.3$ & $19.0-41.0$ \\
\hline Arachidic & $\mathrm{C}_{20: 0}$ & $0.8-3.4$ & $2.2-4.7$ & $0.0-0.3$ \\
\hline Eicosenoic & $\mathrm{C}_{20: 1}$ & $-\quad-2=$ & $9.5-12.4$ & $--2 x=$ \\
\hline Behenic & $\mathrm{C}_{22: 0}$ & - & $4.2-5.3$ & - \\
\hline Lignoceric & $\mathrm{C}_{24: 0}$ & - & $1.1-3.5$ & - \\
\hline
\end{tabular}

Table 1. Fatty acid content of the non-edible oils (mentioned in the text) (\%). diesel, though a mixture of certain percentage (up to $30 \%$ ) of oil with diesel is found to work reasonably well. However, they can be modified to get more suitable fuels that can fully substitute diesel or petrol. One way is by cracking them at higher temperatures on certain metal oxide catalysts, which yields hydrocar-

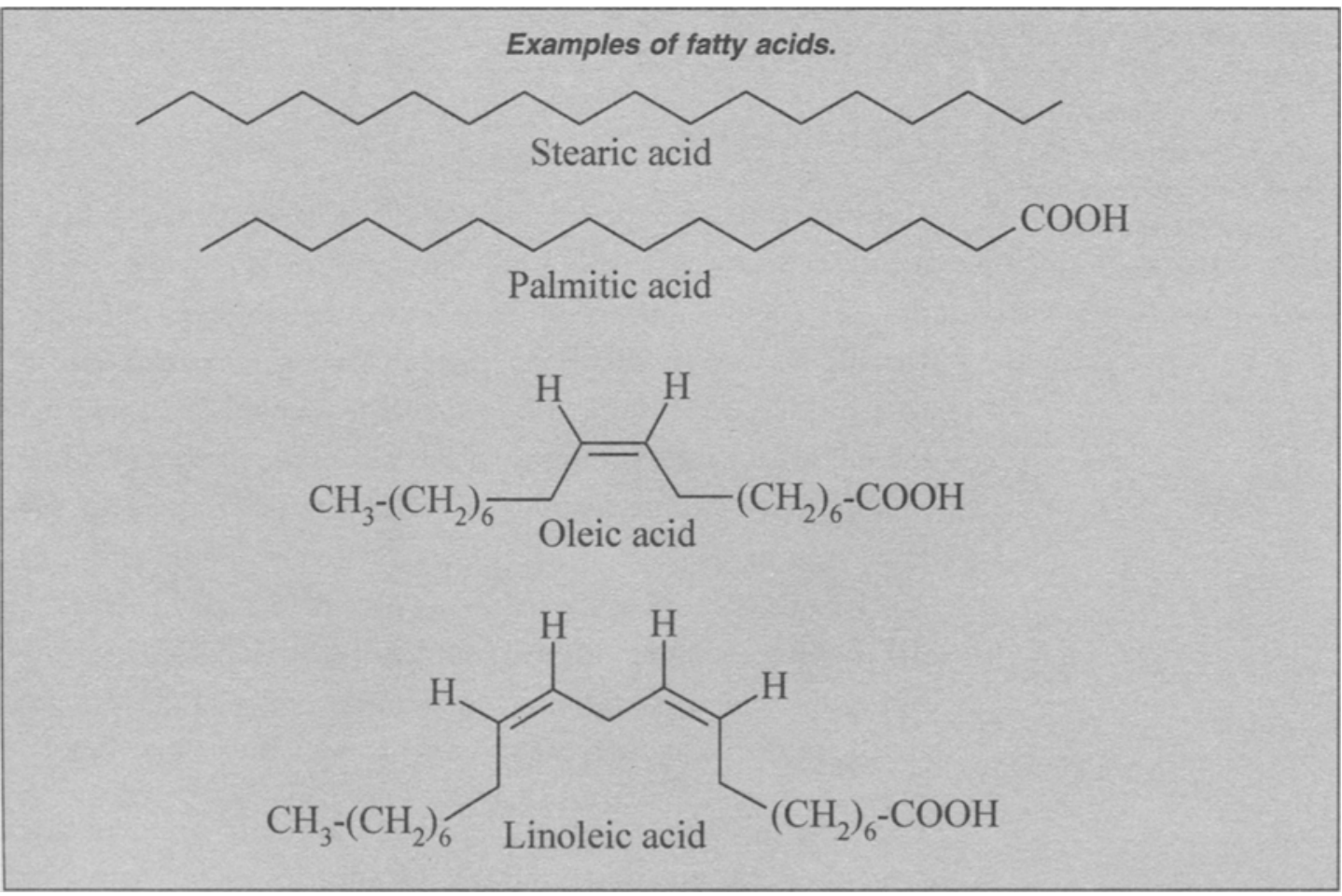




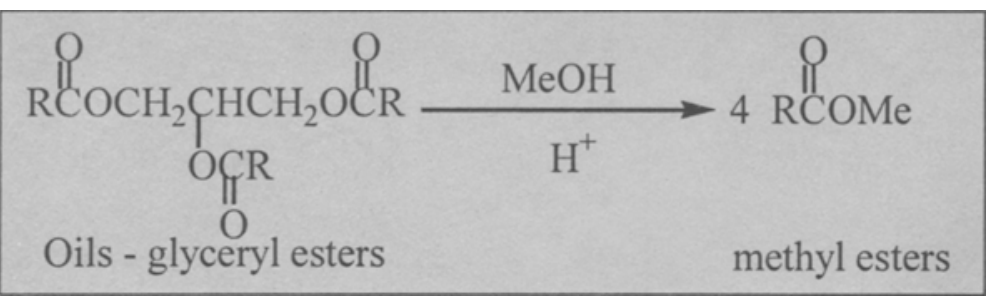

bons having fuel qualities similar to those of petrol/diesel. The other method is a chemical reaction called transesterification. In this process, the glyceryl esters of the fatty acids in the oil are converted into their methyl esters by an acid catalysed reaction of oils with methanol ${ }^{1}$. The methyl esters are better suited to be used as vehicle fuel either in pure form or by blending with diesel.

\section{Ethyl Alcohol}

Ethyl alcohol is another liquid fuel that can be derived from plants. Presently, absolute alcohol cannot be used for running transport vehicles. However, it can be mixed up to $20 \%$ with petrol. The blend, called gasohol, retains the fuel properties of petrol. Alcohol is a cleaner fuel and has the added advantage of being less polluting. Mixing of up to $35 \%$ alcohol in petrol was recommended in India in 1948 itself through Indian Power Alcohol Act.

Alcohol is obtained by the fermentation of carbohydrates. The most efficient carbohydrate producing crop, in terms of solar energy capture per unit land area, is sugar cane. The sugarcane contains a simple carbohydrate, sucrose, a disaccharide. After getting the sugar from the juice, the syrupy residue, called molasses, is used for making alcohol. In all the countries where sugar industry is a major industry, as in Brazil and India, molasses is the most important feedstock for the manufacture of alcohol.

The fermentation process involves action of enzymes, invertase and zymase present in yeast, mainly Saccharomyces cervisiae, on sucrose contained in molasses. Invertase breaks sucrose to its
I $R=$ saturated or unsaturated straight-chain hydrocarbon moiety, occasionally with other functional groups. For example, in stearic acid $\mathrm{R}=\mathrm{C}_{17} \mathrm{H}_{35}$, palmitic acid $R=\mathrm{C}_{15} \mathrm{H}_{31}$, oleic acid, $\mathrm{R}=$ $\mathrm{C}_{17} \mathrm{H}_{33}$, linoleic acid, $\mathrm{R}=\mathrm{C}_{17} \mathrm{H}_{31}$. 


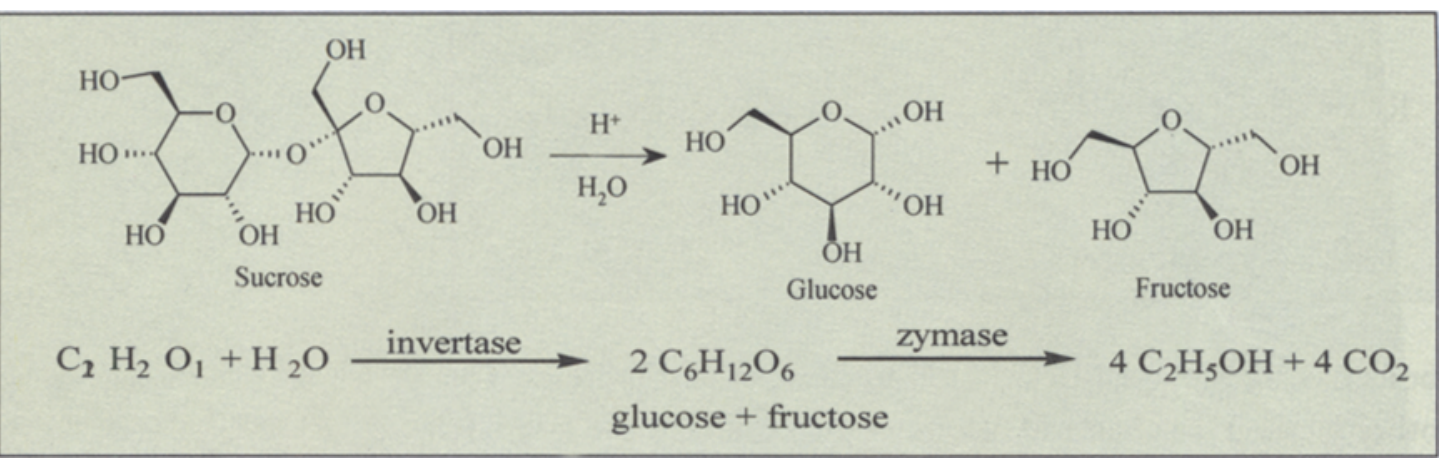

monosaccharide units D-glucose and D-fructose and zymase ferments these simpler sugars to ethyl alcohol.

Other abundant feedstocks for getting fermentable sugars are starch and cellulose. Large quantities of starch are available from tuber crops like potato, tapioca and cassava, and grains like

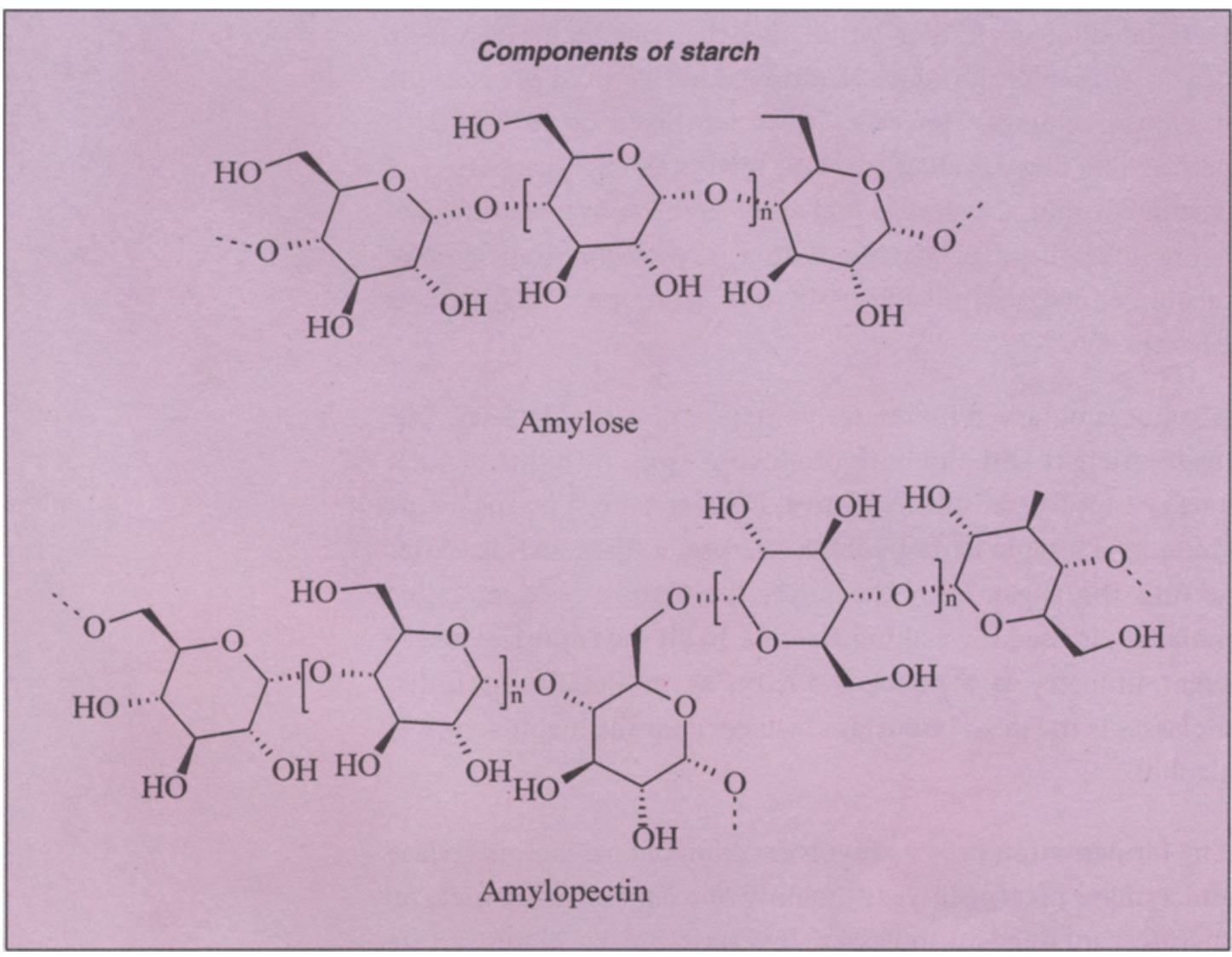




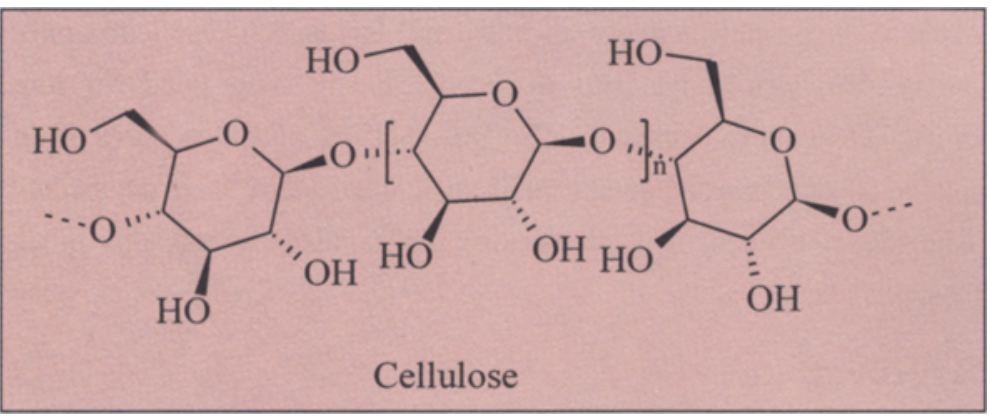

maize (corn) and sorghum. The cellulosic raw materials like wood, agricultural residues, grass, bagasse and other plant material are available in plenty. Both starch and cellulose are polymers of D-glucose, but structurally quite different. Starch can be more easily hydrolyzed than cellulose to the monomeric glucose. The conversion of starch to glucose is achieved by either chemical method, which involves treating with dilute acids, or enzymatically using amylases and amyloglucosidase (diastase or malt).

Much of the cellulosic feedstock is not pure cellulose and contains varying amounts of lignins and other compounds from which cellulose is obtained by delignification procedures, like treatment with alkali, or by 'steam explosion' treatment followed by removal of lignin by methanol or alkali extraction. In another procedure, cellulose is directly degraded to glucose by treating 'milled' lignocellulose suspended in water with Trichoderma reesei cellulases.

Glucose solution obtained from the hydrolysis of starch or degradation of lignocellulose is fermented to ethyl alcohol by enzymatic procedures mentioned earlier.

Another source of ethanol is the sap (sweet juice) of several species of palm. Tapping palmyra (Figure 1) and wild date palms for toddy and jaggery in India is well known. The sugars in the sweet sap can be directly fermented to alcohol. Fermentation is actually spontaneous, as the enzymes required are already present in the sap. It has been observed that palms are capable of yielding more alcohol per unit area of land than sugarcane.
Figure 1.

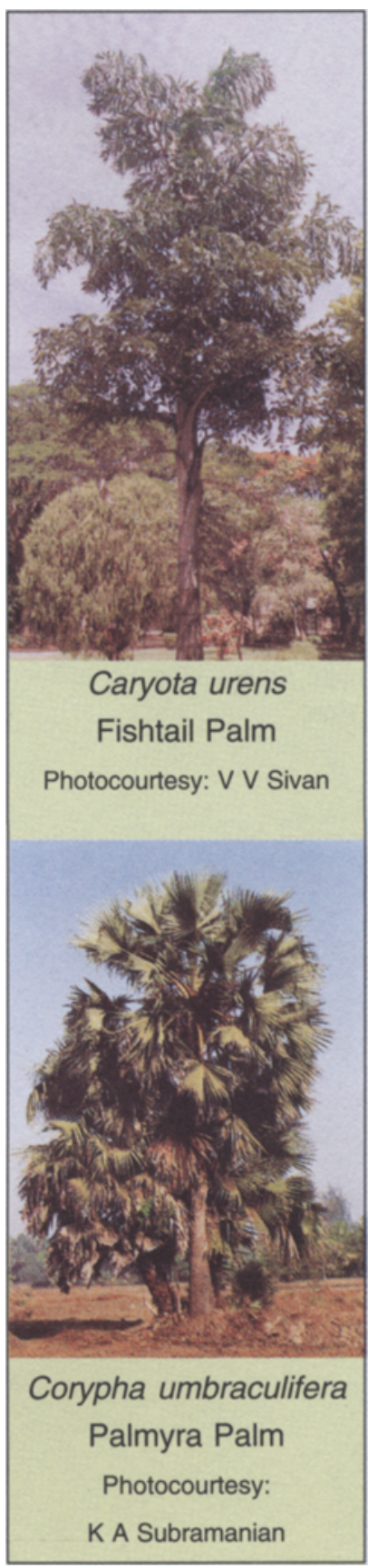


${ }^{2}$ Hydrocarbons present in petrol represent essentially the $C_{5}-C_{10}$ fraction of petroleum, boiling in the range $40-200^{\circ} \mathrm{C}$. The hydrocarbon isooctane. $\left(\mathrm{CH}_{3}\right)_{3} \mathrm{C}-\mathrm{CH}_{2}-$

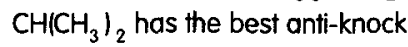
property, with 'octane number' of 100.

${ }^{3}$ The constituents of diesel are hydrocarbons of $>C_{12}$ having a boiling range of about 250 $350^{\circ} \mathrm{C}$.
Moreover the palms grow on marginal lands, which means palm cultivation would not put pressure on the land used for food crops. However, presently the cultivation of palm trees mentioned above is neither scientifically sound nor well organized. Therefore, obtaining fuel alcohol from palms at present is not practicable.

\section{Hydrocarbons}

We are so much used to petrol ${ }^{2}$ (also called gasoline in North America) and diesel ${ }^{3}$ (also called fuel oil) as transport fuel that we think of converting any renewable source of energy into these fuels. Of course, petroleum fuels are the most convenient for the working of internal combustion engine. Therefore it would be highly desirable if we can produce petrol-like hydrocarbons from plants. Considerable work has been done on the cultivation of 'petroleum plantations'.

There are a large number of plants that produce hydrocarbons. When these plants are scraped or injured or a slit is made in the trunk or branch, a fluid oozes. This 'latex' is composed mainly of hydrocarbons. Rubber tree is a well-known example of a hydrocarbon-producing plant. Cultivation of various latex yielding plants, called 'petroleum plantation', has been proposed for the extracting of hydrocarbons that can be converted into petrollike fuel or other hydrocarbon feedstock. Even if the plants do not yield latex profusely, they can be harvested for getting hydrocarbons. In this case, the harvested plants are dried and the dried mass is extracted with solvents, which are themselves hydrocarbons or chlorinated hydrocarbons. By this procedure the hydrocarbons in the plant biomass will be released into the solvent. After removing the solvent, the remaining residue is converted into transport fuel by further processes involving catalytic cracking, distillation, etc.

The plants that are promising to yield 'bio-crude' are the members of the family of Euphorbiaceae. Many of these species are being cultivated on experimental basis in the U.S.A, India, Japan and a few other countries. The succulent species like 
Euphorbia tirucalli (Figure 2) 2 E. antiquorum, E. nivulia, E. milii and Pedilanthes tithymaloides are grown in Karnataka and other parts of South India as hedge plants or ornamental plants. They are recommended to be grown as 'petrocrops'. Non-succulent species such as Euphorbia geniculata, E. corrigioloides, E. pulcherrima, Synadenium grantii (Figure 3) are also grown in South India. In other parts of India, Euphorbia antisyphilica, Calotropis procera, Grystotegia glandiflora are grown, which are quite promising as sources of hydrocarbons.

Maninot esculenta (tapioca) is a latex yielding tuber crop. It can, therefore, be a source of both alcohol and hydrocarbons. Its tuber can be used for alcohol production and other parts of the plant for hydrocarbon processing.

The extractable hydrocarbon content that is useful as petrol substitute in these plants varies from about $3 \%$ to $9 \%$. Most of them are higher molecular weight hydrocarbons that contain more than 25 carbon atoms. They have to be broken down into smaller molecules for using them as transport fuels. Catalytic cracking is a well-established method by which higher molecular weight hydrocarbons are converted to petrol-like lower molecular weight hydrocarbons.

Terpenoid hydrocarbons are obtained from many different types of plants. Turpentine oil and lemon grass oil are just two examples of these. However, since they have other important applications, they are not considered for using as fuel.

\section{Conclusion}

The three types of liquid fuels that are described here can no doubt replace petrol or diesel wholly or partially as blends for transport vehicles or other purposes. For all the three fuels, the sources are the plants. Considerably complex technology is involved at present in converting the biomass into liquid fuel. The non-edible fatty oils and ethanol can, of course, be produced with simpler technology. Only sugar and certain starches are conveniently fermented to alcohol. However, as they are also

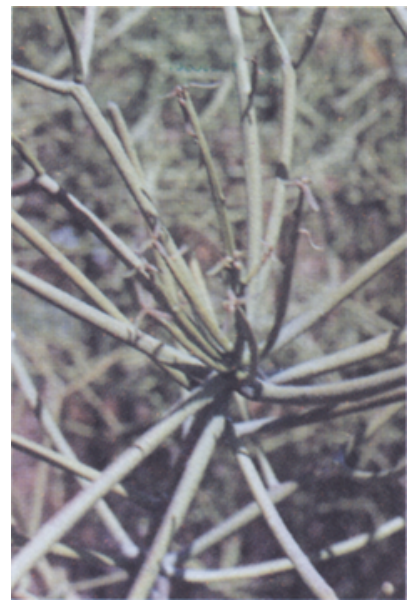

Figure 2. Family: Euphorbiaceae.

Euphorbia tirucalli (L)

Photo courtesy: M C Gayathri

Figure 3. Family: Euphorbiaceae.

Synadenium grantii

Photo courtesy: M C Gayathri

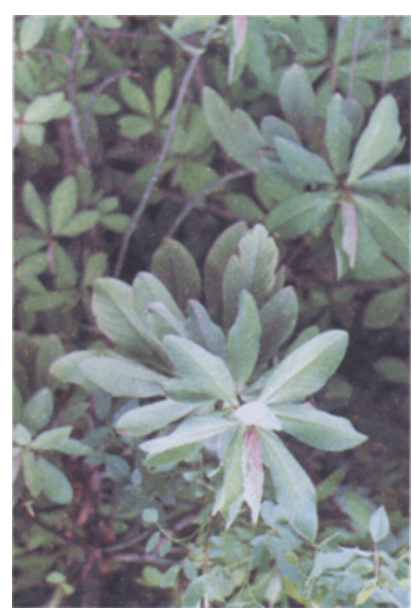




\section{Box 1.}

Many trees and other forms of plants store 'food' in the endosperms of their seeds for the use of the seedlings immediately after germination. This stored food contains carbohydrates, lipids, proteins and steroids in varying quantities. We grow agricultural and horticultural crops to obtain the above for our daily food use and for our cattle. In India carbohydrates and lipids from seeds could also contribute significantly as renewable energy resources. However this aspect is not well recognised. Therefore to develop lipids and carbohydrates (commonly known as oil and starch respectively) from the seeds as a resource, SuTRA (Sustainable Transformation of Rural Areas), a programme unit of SID (the Society for Innovation and Development), Indian Institute of Science, Bangalore, has been popularising the direct use of oil in diesel engines for a variety of applications and of the starch in biogas plants.

Oils of honge, Pongamia pinnata (see Figure a), neem and mahua, Madhuca indica have been commonly available in most parts of India for a long time as fuels for illumination purposes. However to use them as diesel substitutes in transport vehicles these oils need to be (a) degummed (refined) to remove the drying components in them, (b) thoroughly filtered to remove the particulates, and (c) warmed before being fed into the fuel injector to reduce the viscosity to acceptable levels. Since most seed oils are triglycerides of natural fatty acids like

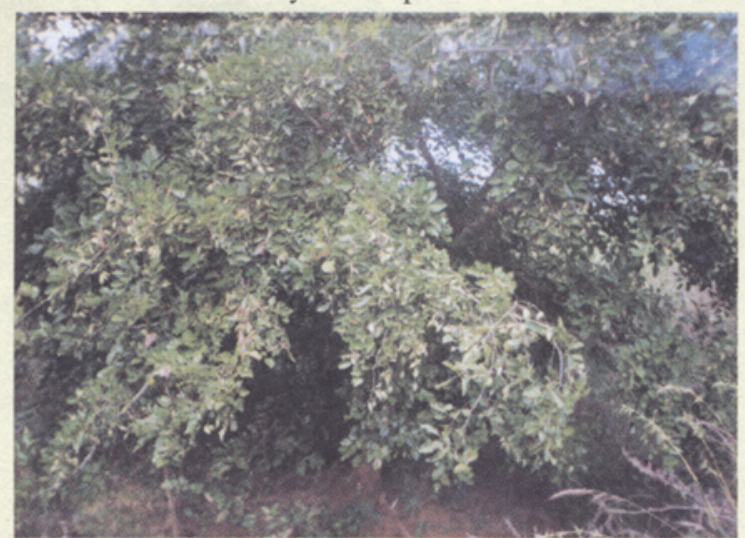

Top:

Honge Tree

Right:

Honge Fruit

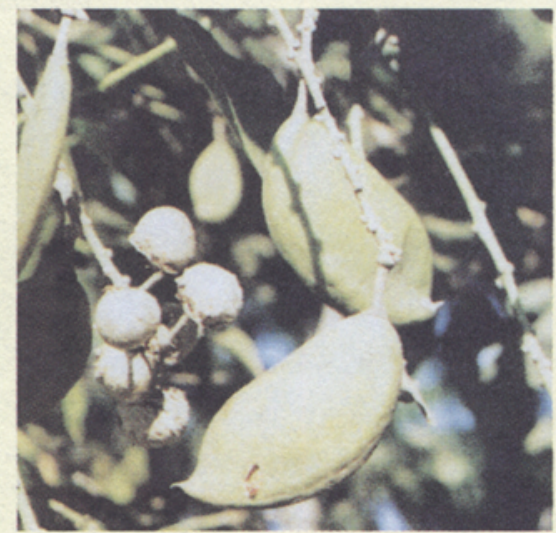

stearic, palmic, etc., literature recommends esterification with ethyl alcohol and removal of the glycerols. The process reduces the average molecular length to about one third, which facilitates combustion. Such esters are already being marketed in a limited way in Europe and North America under the name 'bio-diesel'. On the other hand, for several years now at least two firms in Europe have been selling conversion kits for using vegetable oils directly in diesel cars to cut the fuel cost to almost one-half. Their success indicates that esterification is an avoidable step.

In the last two and a half years SuTRA has used about 8 tons of honge oil in more than 10 enginegenerator sets of capacity ranging from 3.7 to 60 $\mathrm{kVA}$, in a few engine-pump sets, in a tractor, and also for running a diesel jeep for about $2000 \mathrm{~km}$. The oil was used neat after thorough filtering using bolting cloth. No modifications were necessary on the engines. However the jeep requires a kit to help in easy switching from oil to diesel when required. Engine-generators consume about $10 \%$ more honge oil by volume as compared to diesel

Box 1. continued 
Table A. Comparison with diesel

$\begin{array}{llllll}\begin{array}{l}\text { SI. } \\ \text { No. }\end{array} & \text { Particulars } & \begin{array}{l}\text { Honge } \\ \text { (unfiltered) }\end{array} & \begin{array}{l}\text { Honge } \\ \text { (degummed) }\end{array} & \text { Diesel } & \text { Neem } \\ \text { 1. } & \text { Saponification value } & 178 & 186 & \text { NIL } & 196 \\ \text { 2. } & \text { Iodine value } & 116 & 95 & 38 & 110 \\ 3 . & \text { Acid value } & 2.3 & 1.6 & (\mathrm{NIL}) & 1.4 \\ 4 . & \text { Colour in } 1 \text { inch cell }(\mathrm{Y}+5 \mathrm{R}) & 50 & 50 & 102 & 50 \\ 5 . & \text { Specific gravity } & 0.92 & 0.93 & 0.84 & 0.92 \\ 6 . & \text { Refractive index } & 1.48 & 1.48 & 1.47 & 1.48 \\ \text { 7. } & \text { Moisture \& volatile matter } & 0.05 & 0.2 & 25 & 0.04 \\ 8 . & \text { Viscosity at } 25^{\circ} \mathrm{C}(\text { centi stokes) } & 85 & 89 & 8.5 & 86 \\ 9 . & \text { Cloud point }\left({ }^{\circ} \mathrm{C}\right) & 15 & 15 & 13 & 13 \\ 10 & \text { Pour point }\left({ }^{\circ} \mathrm{C}\right) & -1 & -1 & 1 & 1 \\ 11 . & \text { Gross calorific value }(\mathrm{k} \mathrm{Cal} / \mathrm{kg}) & 9,340 & - & 10,500 & 9,000\end{array}$

whereas the number of kilometres per litre in the case of the jeep is not reduced (Table A). In all the cases the engines could also start on honge. The engine exhaust appears less smoky on visual inspection as compared to diesel. The above experience of SuTRA indicates the potential to get started with honge oil as diesel substitute while more experience is being accumulated with other oils. (Also see filler item on $\mathrm{p} .46)$

Department of Mechanical Engineering, IISc, Bangalore 560 012, Email:udipi@sutra.iisc.ernet.in

important food items, diverting them for power alcohol production would be severely restricted. Moreover, to fulfill the growing demand for fuels a large area of land has to be set aside for such purposes. This also has limitations. Using cellulosic and lignocellulosic biomass like wood and agricultural waste for alcohol production requires more involved chemical and biochemical technology and has therefore its limitations.

The hydrocarbon yielding plants can be grown on marginal lands. In that sense it is fine. But extraction of the hydrocarbons and their conversion to a more useful form are difficult. To make this viable, a lot of technological advancement has to be achieved. Genetic improvement of the plants or improved agronomic practices to yield more and better quality hydrocarbons are to be undertaken. There is still a long way to go before we can fulfill all our liquid fuel needs from 'petroleum plantations'.
Addresss for Correspondence G Nagendrappa Department of Chemistry Bangalore University Bangalore 560 001, India. 